\title{
Methylphenidate Fast Dissolving Films: Development, Optimization Using Simplex Centroid Design and In Vitro Characterization
}

\author{
(1) Biswajit BASU1*, (1) Ankur MANKAD², (1) Ayon DUTTA ${ }^{1}$ \\ 1Bengal School of Technology, Department of Pharmaceutics, West Bengal, India \\ 2Atmiya University, Faculty of Paramedical Sciences, Department of Pharmaceutics, Gujarat, India
}

\begin{abstract}
Objectives: The focus of this study was to design and optimize methylphenidate hydrochloride mouth dissolving film (MDF) that can be beneficial in an acute condition of attention deficit hyperactivity disorder (ADHD) and narcolepsy.

Materials and Methods: Solvent casting method was used for the preparation of this film. Optimization of the effect of independent variables such as the number of polymers and active pharmaceutical ingredients [hydroxypropyl methyl cellulose (HPMC) E5, HPMC E15, and maltodextrin], \% of drug release, disintegration time, and tensile strength of the film done using simplex centroid design. Complex formation of the film was tested using fourier-transform infrared spectroscopy and differential scanning calorimetry study. The multiple regression analysis was obtained from equations of the results that adequately describe influence of the independent variables on the selected responses. Polynomial regression analysis, contour plots, and 3-D surface plots were used to relate dependent and independent variables.

Results: Experimental results indicated that different polymer amounts had complex effects on \% drug release from the film, disintegration time as well as the tensile strength of the film. The observed responses were in near alignment with expected values calculated from the developed regression equations as shown by percentage relative error. Final formulation showed more than $95 \%$ drug release within 2 min and was shown to disintegrate within a minute that had good tensile strength.

Conclusion: These findings suggest that MDF containing methylphenidate hydrochloride is likely to become a choice of methylphenidate hydrochloride preparations for treatment in ADHD and narcolepsy conditions.
\end{abstract}

Key words: HPMC, maltodextrin, mouth dissolving film, ADHD, simplex centroid design

\section{INTRODUCTION}

Oral drug administration has been most convenient and commonly recognized routes of delivery of most medicinal agents since the dawn of time. Oral drug formulations are solid and liquid preparations that are taken orally, chewed or swallowed, and travel into the gastrointestinal tract for post buccal absorption.' Nowadays, the most common solid oral dosage types used today are tablets and capsules, which include traditional tablets, controlled-release tablets, along with hard and soft gelatin capsules. ${ }^{2,3}$

One of the major problems correlated with use of these oral dosage forms is the time required for onset of action, which is at least half an hour in case of conventional dosage forms and even more in the controlled and sustained release dosage forms. Dysphagia (difficulty in swallowing) is a chronic problem in people of all ages, but it is more prevalent in the elderly and pediatric patients due to physiological differences. Uncooperative, mentally ill, and patients suffering from fatigue, vomiting, motion sickness, allergic attack or coughing are some of the other groups who have issues. This issue affects $35-50 \%$ of the population according to reports. ${ }^{4,5}$

These concerns created mouth-dissolving films (MDF), a new kind of solid oral dosage medium. These delivery mechanism degrades or disintegrates quickly in mouth, requiring of water 
to facilitate swallowing. Such technologies make it easier for those with swallowing problems as well as the public to take their drugs. Upon ingestion, saliva serves to rapidly disperse/ dissolve the MDF. The saliva containing dissolved medicament is absorbed from mouth, pharynx, and esophagus. Because of the above-mentioned advantages, bioavailability of drugs is significantly increased than those observed from conventional dosage forms such as tablets and capsules. ${ }^{2,3}$

Methylphenidate hydrochloride is a psychostimulant drug. The drug is useful in the condition of attention deficit hyperactivity disorder (ADHD), a condition that requires immediate medication. By blocking dopamine delivery or carrier proteins, this drug prevents dopamine uptake in central adrenergic neurons. It also induces a heightened sympathomimetic activity in central nervous system by operating on brain stem arousal system and cerebral cortex. Methylphenidate hydrochloride is a biopharmaceutics classification system class-I (high permeability and solubility) drug and its bioavailability is only $11-52 \%$ due to its hepatic metabolism. Therefore, main objective of this work was to provide immediate release of the psychostimulant drug methylphenidate $\mathrm{HCl}$ for immediate action in ADHD condition in order to improve patient compliance and to avoid hepatic first-pass metabolism of the drug. ${ }^{4,5}$

Therefore, the current study was conducted to develop MDFs of methylphenidate hydrochloride to provide quicker onset of action in the condition of ADHD. ${ }^{4}$

\section{MATERIALS AND METHODS}

Methylphenidate hydrochloride was given as a gift sample from Ipca Laboratories Ltd., Mumbai, India. Different hydroxypropyl methyl cellulose (HPMC) grades were gifted from Colorcon Asia Pvt. Ltd. Goa, India. Maltodextrin was purchased from Himedia Laboratories Pvt. Ltd, Mumbai, India.

\section{Calibration curve of methylphenidate $\mathrm{HCl}$}

Preparation of standard stock solutions

Methylphenidate $\mathrm{HCl}(100 \mathrm{mg})$ was weighed accurately into a $100 \mathrm{~mL}$ volumetric flask and dissolved with phosphate buffer $\mathrm{pH}$ 6.8. The volume was made up to $100 \mathrm{~mL}$ with the same solution to get a concentration of $1000 \mu \mathrm{g} / \mathrm{mL}(1 \mathrm{mg} / \mathrm{mL}){ }^{6}$

\section{Scanning of drugs}

Ultraviolet (UV) spectrum was taken of the stock solution between wavelengths of 200-400 nm. It gave a peak at 257.2 $\mathrm{nm}$ and the same was selected as $\lambda_{\max }$. The absorption maxima of methylphenidate hydrochloride in a $\mathrm{pH}$ buffer of 6.8 are shown in Figure 1.7

\section{Preparation of calibration curve}

The stock solution was diluted with a pH buffer of 6.8 to get a concentration range of 100 to $1000 \mu \mathrm{g} / \mathrm{mL}$. Absorbance of these solutions was measured against a blank at $257.2 \mathrm{~nm}$ using a UV visible spectrophotometer (Shimadzu Corporation, Japan) and the absorbance values are summarized in Table 1. The calibration curve, which was plotted against absorbance versus drug concentrations, is given in Figure 2.8,9

\section{Preparation of mouth dissolving film of methylphenidate $\mathrm{HCl}$}

Calculation of dose of methylphenidate $\mathrm{HCl}$

Methylphenidate is an effective drug against ADHD treatment with a good safety profile; evidence shows that dose optimization can improve the safety and effectiveness of treatment. Dose optimization is used widely in general medicine and psychiatry to achieve optimum therapeutic impact, thus minimizing the likelihood of adverse effects. Dose optimization is typical with virtually all psychotropic drugs and may be critical, particularly in therapeutic dose-response relationships with high individual heterogeneity, such as the use of stimulants to manage ADHD. Genetic diversity, patient's weight, age, sex, drug-induced resistance, and associations with other drugs or medical conditions are all considerations that can affect the need for dosage optimization..$^{10}$

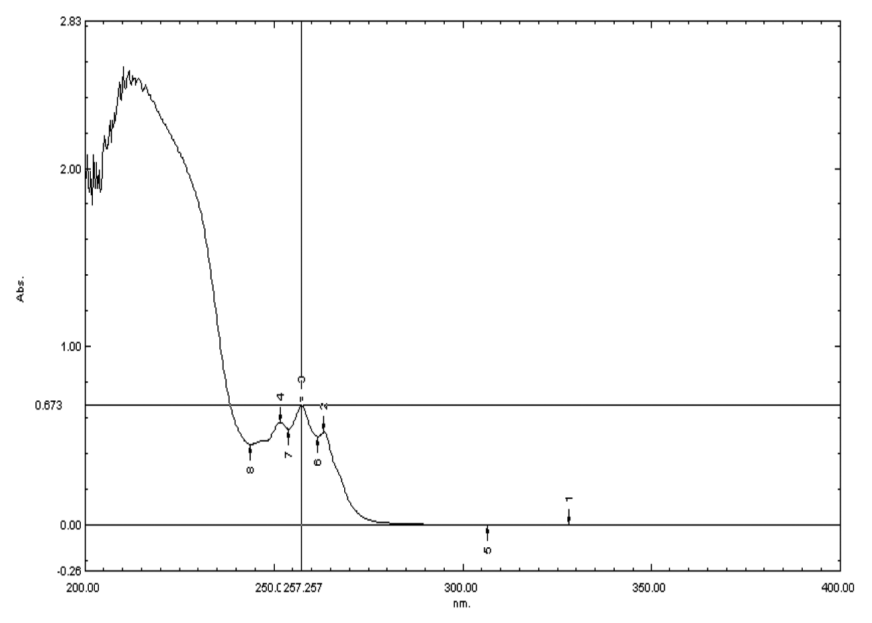

Figure 1. Absorption maxima of methylphenidate $\mathrm{HCl}$ in $\mathrm{pH} 6.8$ phosphate buffer

Table 1. Calibration data of drug in pH 6.8 phosphate buffer at $257.2 \mathrm{~nm}$

\begin{tabular}{|c|c|c|c|c|}
\hline \multirow{2}{*}{$\begin{array}{l}\text { Concentration } \\
(\mu \mathrm{g} / \mathrm{mL})\end{array}$} & \multicolumn{3}{|c|}{ Absorbance } & \multirow{2}{*}{$\begin{array}{l}\text { Mean } \\
\text { absorbance* }^{*}\end{array}$} \\
\hline & I & II & III & \\
\hline 0 & 0 & 0 & 0 & 0 \\
\hline 100 & 0.056 & 0.084 & 0.068 & $0.0693 \pm 0.014$ \\
\hline 200 & 0.119 & 0.140 & 0.131 & $0.13 \pm 0.013$ \\
\hline 300 & 0.186 & 0.214 & 0.205 & $0.2017 \pm 0.014$ \\
\hline 400 & 0.251 & 0.289 & 0.271 & $0.2703 \pm 0.019$ \\
\hline 500 & 0.327 & 0.369 & 0.349 & $0.3483 \pm 0.021$ \\
\hline 600 & 0.402 & 0.443 & 0.414 & $0.4197 \pm 0.021$ \\
\hline 700 & 0.456 & 0.485 & 0.471 & $0.4707 \pm 0.014$ \\
\hline 800 & 0.544 & 0.559 & 0.552 & $0.5517 \pm 0.017$ \\
\hline 900 & 0.602 & 0.649 & 0.623 & $0.6247 \pm 0.023$ \\
\hline 1000 & 0.664 & 0.682 & 0.673 & $0.673 \pm 0.014$ \\
\hline
\end{tabular}

*Results are shown in mean \pm SD $(n=3), S D$ : Standard deviation 
Dosage to be used in the film was measured using the equation below."

Drug input $=\mathrm{C}_{\mathrm{ss}} \times \mathrm{K}_{\mathrm{e}} \times \mathrm{V}_{\mathrm{d}}$

$=133 \mu \mathrm{g} \mathrm{L}-1 \times 0.3465 \mathrm{hr}-1 \times 2.7 \mathrm{~L}$

$=6872.399 \mu \mathrm{g} \mathrm{hr}-1=6.87 \mathrm{mg}$

Here, $C_{s s}=133 \mu \mathrm{g} \mathrm{L}^{-1}$

$\mathrm{V}_{\mathrm{d}}=2.7 \mathrm{~L}$

$\mathrm{K}_{\mathrm{e}}=0.3465$, where $\mathrm{C}_{\text {ss }}$ is the concentration at a steady state.

$\mathrm{K}_{\mathrm{e}}=$ Elimination rate constant

$\mathrm{V}_{\mathrm{d}}=$ Volume of distribution

Dose of methylphenidate $\mathrm{HCl}$ is $7.17 \mathrm{mg}$. Therefore, $7.17 \mathrm{mg}$ dose of methylphenidate $\mathrm{HCl}$ was required in a film containing $4 \mathrm{~cm}^{2}$ area. Total area of $9.4 \mathrm{~cm}$ diameter petri dish was 69.43 $\mathrm{cm}^{2}$. So, the amount of drug present in $69.43 \mathrm{~cm}^{2}$ of petri dish was $124.42 \mathrm{mg}$ for all formulations. Therefore, the amount of methylphenidate $\mathrm{HCl}$ in each film $\left(4 \mathrm{~cm}^{2}\right)$ was $7.17 \mathrm{mg} \cdot 12,13$

\section{Preparation of film by solvent casting method}

Various methods have been used for film preparation. Among the methods, the solvent casting method is the widely used method to get a good and smooth film. MDF of methylphenidate $\mathrm{HCl}$ was made by the solvent casting method. The aqueous solution was prepared by dissolving the chosen polymers in $25 \mathrm{~mL}$ purified water and allowed to rest for 1 hour to eliminate any trapped air bubbles. Then, the active pharmaceutical ingredients and plasticizer were dissolved in this polymeric solution. After that, the mixture solution was poured into a silicone petri dish and dried in a $50^{\circ} \mathrm{C}$ oven for 24 hours. The film was then gently withdrawn from the petri dish and examined for flaws. The samples were wrapped in butter paper and aluminum foil and stored in a desiccator until further analysis. ${ }^{14-17}$

\section{Preformulation study}

\section{Melting point}

Melting point of methylphenidate $\mathrm{HCl}$ was measured by digital melting point apparatus. The drug sample was filled in a capillary tube and stored using a mercury thermometer in an

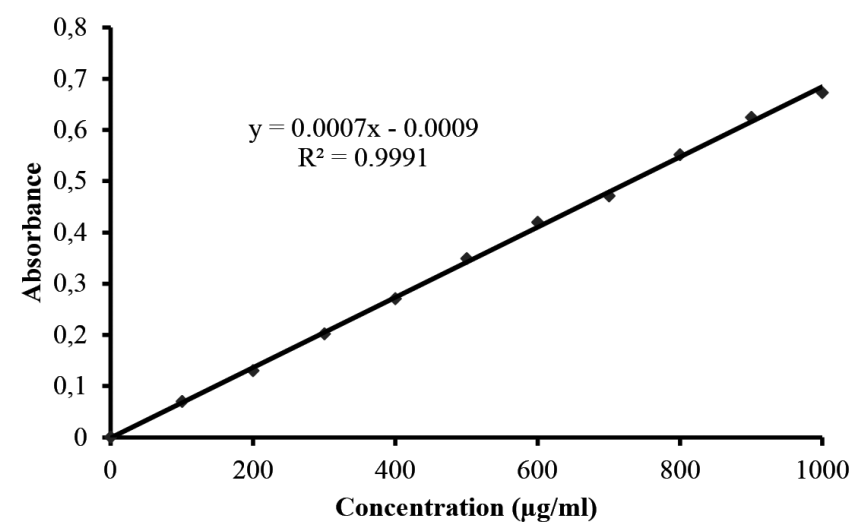

Figure 2. Standard curve of methylphenidate $\mathrm{HCl}$ in phosphate buffer $(\mathrm{pH}$ 6.8) aluminum block of the apparatus. The block was heated by two elements clamped to the sides in the apparatus and the sample tube was viewed through the magnifying lens by adjusting a dark or bright background. Temperature was recorded at which the sample started to melt and the point, at which it was completely melted. ${ }^{18,19}$

\section{Partition coefficient}

Methylphenidate is soluble in alcohol, ethyl acetate, and ether. Hence, ether is chosen for determination of partition coefficient. For this purpose, ether and water were saturated with each other for the period of $24 \mathrm{~h}$ in a $500 \mathrm{~mL}$ volumetric flask. In a $100 \mathrm{~mL}$ volumetric flask, 10\% (w/v) of the drug was transferred to mixture of the above-saturated solution and stirred for 24 hours at room temperature on a rotary shaker. After 24 hours of equilibrium, the system was centrifuged for 15 minutes at 3000 rpm for 15 minutes. Concentration of methylphenidate $\mathrm{HCl}$ in ether and water was analyzed by a UV-visible spectrophotometer at $257.2 \mathrm{~nm}$ after appropriate dilution with methanol. Partition coefficient was determined using the equation below. The experiment was replicated thrice. ${ }^{19}$

Partition coefficients $=\frac{\text { Concentration of drug in ether }}{\text { Concentration of drug in water }}$

\section{Optimization of mouth dissolving film components}

The placebo films were made using polymers like maltodextrin, HPMC E3, HPMC E5, and HPMC E15 by solvent-casting method. Polymers were selected from the abovementioned placebo film by an appearance via visual inspection and disintegration time. An identical approach was used to optimize plasticizers (glycerin, propylene glycol) using the previously optimized concentration of respective components. The plasticizer was optimized based on film tensile strength, folding endurance, and disintegration time. ${ }^{20,21}$

\section{Statistical analysis}

Statistical analysis has been performed using simplex centroid design.

\section{Simplex centroid design}

The use of simplex centroid experimental designs in pharmaceutical research is well known. They are especially useful in formulation optimization procedures, where the overall number of ingredients being considered must remain constant. In the films, the total amount of polymer, if changed, can lead to a large extent change in the mechanical properties of the film, so, simplex centroid is the appropriate design to be applied to the film formulation. The values of dependent and independent variables can be used to develop a polynomial first-order linear interactive model.

$\mathrm{Y}=\mathrm{B}_{1} \mathrm{X}_{1}+\mathrm{B}_{2} \mathrm{X}_{2}+\mathrm{B}_{3} \mathrm{X}_{3}+\mathrm{B}_{12} \mathrm{X}_{1} \mathrm{X}_{2}+\mathrm{B}_{23} \mathrm{X}_{2} \mathrm{X}_{3}+\mathrm{B}_{13} \mathrm{X}_{1} \mathrm{X}_{3}+\mathrm{B}_{123} \mathrm{X}_{1} \mathrm{X}_{2} \mathrm{X}_{3}$ where $Y$ is the response parameter and $B i$ are the projected coefficients for factor $X_{i}$. The main effects $\left(X_{1}, X_{2}\right.$, and $\left.X_{3}\right)$ represent average results of changing one factor from its low to high value at a time. The interaction terms $\left(X_{1} X_{2}, X_{2} X_{3}, X_{1} X_{3}\right.$, 
$\mathrm{X}_{1} \mathrm{X}_{2} \mathrm{X}_{3}$ ) show how the response changes when two or more factors are changed simultaneously (Tables 2, 3). ${ }^{22-24}$

Other common ingredients used for each formulation

Other ingredients used include propylene glycol, $0.5 \mathrm{~mL}$, as a plasticizer, and brilliant blue as color. Glycerin was used to the lubrication the petri dish to facilitate smoother peeling of the film.

\section{Evaluation parameters for prepared films}

\section{Scanning of methylphenidate $\mathrm{HCl}$ in UV spectrophotometer}

Scanning of methylphenidate $\mathrm{HCl}$ has been performed. ${ }^{25} \mathrm{~A}$ UV spectrum was run between the wavelengths $200-400 \mathrm{~nm}$ and is described in Figure 1.

\section{Calibration curve of methylphenidate $\mathrm{HCl}$}

Methylphenidate $\mathrm{HCl}(100 \mathrm{mg}$ ) was weighed accurately into a $100 \mathrm{~mL}$ volumetric flask and dissolved with phosphate buffer $\mathrm{pH}$ 6.8. The volume was made up to $100 \mathrm{~mL}$ with the same solution to get a concentration of 1000 $\mu \mathrm{g} / \mathrm{mL}$. From this, solutions of concentrations ranging from $100 \mu \mathrm{g} / \mathrm{mL}$ to $1000 \mu \mathrm{g} / \mathrm{mL}$ were prepared and their absorbance was measured at $257.2 \mathrm{~nm}$ wavelength in a UV spectrophotometer. ${ }^{25,26}$

\section{Thickness measurement}

A screw gauge was used to measure the thickness of the $\operatorname{MDF}\left(2 \times 2 \mathrm{~cm}^{2}\right)$. Each film's thickness was measured in three locations and the standard deviation (SD) was estimated. ${ }^{27}$

\section{Drug content uniformity}

A $4 \mathrm{~cm}^{2}$ MDF was cut into small pieces and placed in a graduated glass-stoppered flask with $10 \mathrm{~mL}$ of $6.8 \mathrm{pH}$ phosphate buffer. The flask was kept for $24 \mathrm{hrs}$. The solution from the flask was filtered through Whatman filter paper and the amount of drug

\section{Table 2. Independent variables and their respective levels}

\begin{tabular}{lllll} 
Independent variables & 0 & 0.33 & 0.5 & 1 \\
\hline HPMC E5 (X1) & 217 & 250 & 267 & 317 \\
\hline HPMC E15 (X2) & 150 & 183 & 200 & 250 \\
\hline Maltodextrin (X3) & 300 & 333 & 350 & 400 \\
\hline
\end{tabular}

HPMC: Hydroxypropyl methyl cellulose present was determined by UV spectrophotometric method at $257.2 \mathrm{~nm}$ wavelength. ${ }^{28}$

\section{Weight variation}

Three films of size $\left(2 \times 2 \mathrm{~cm}^{2}\right)$ from every batch of MDF were weighed on an electronic balance (Citizen CY 220C, Mumbai, India) and the average weight with SD was calculated. ${ }^{29,30}$

\section{Tensile strength}

Tensile strength was used to precisely calculate the mechanical properties of polymeric MDF. Using a handcrafted tensile strength instrument, the tensile strength of the MDF was measured. MDF was then applied to the assembly and the weights needed to split was measured. The following formula was used to measure tensile strength (formula 1).31,32

T.S.= Break force/A

where $A=$ Cross-sectional area of the film

\section{Percentage elongation}

After calculating tensile strength of the film, percentage elongation was determined using the formula below (formula 2). ${ }^{32}$

Percentage elongation $=\frac{\left(\mathrm{L}_{\mathrm{F}}-\mathrm{L}_{\mathrm{O}}\right)}{\mathrm{L}_{\mathrm{O}}} \times 100$

Here, $L_{F}=$ final length, $L_{0}=$ initial length

\section{Moisture content (\%)}

This measure was also used to determine the film's credibility in dry weather. A film with a surface area of $4 \mathrm{~cm}^{2}$ was cutout, weighed, and placed in a desiccator containing fused anhydrous calcium chloride. The films were removed and reweighed after 24 hours. Formula 3 was used to calculate the percentage moisture content of the film. ${ }^{33,34}$

$\%$ Moisture content $=\frac{\text { Initial weight }- \text { Final weight }}{\text { Initial weight }} \times 100$

\section{\% Moisture uptake}

The formulation was exposed to an atmosphere of $84 \% \mathrm{RH}$ at $28^{\circ} \mathrm{C}$ for three days using a saturated solution of $\mathrm{NaCl}$. After three days the films were removed, weighed and the percentage moisture absorbed was calculated. Calculated the

Table 3. Simplex centroid design

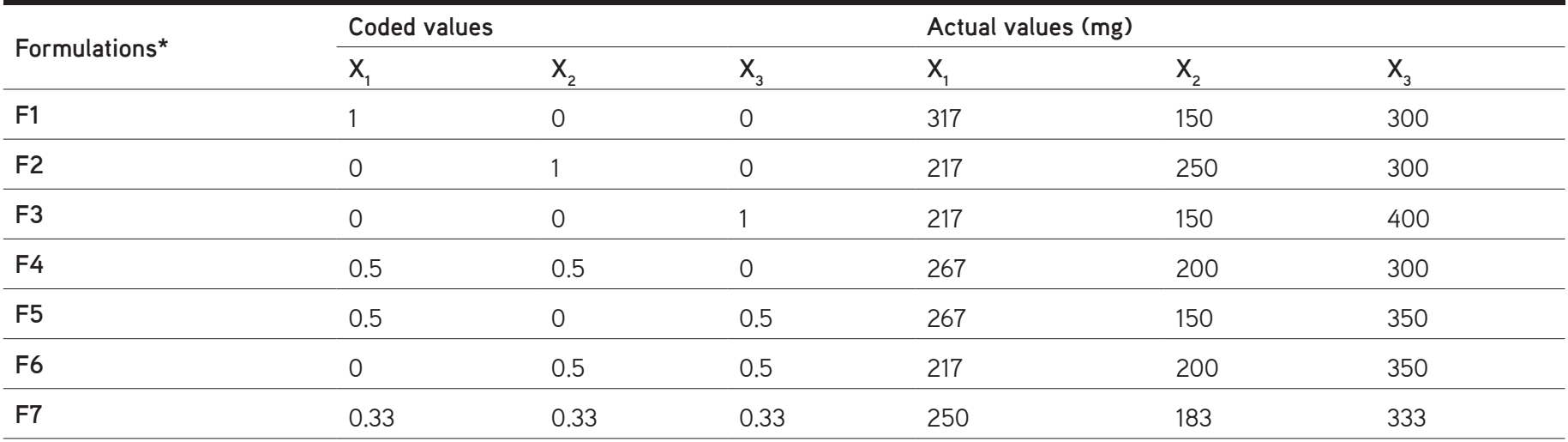


average percentage moisture absorption of each film using the following formula $4 .^{34}$

$\%$ Moisture uptake $=\frac{\text { Final weight }- \text { Initial weight }}{\text { Initial weight }} \times 100$

\section{In vitro disintegration time}

The test was carried out using a slightly modified version of the procedure described by Mishra and Amin ${ }^{20}$. A glass petri dish containing $10 \mathrm{~mL}$ of distilled water was used to hold the film size needed for dosage distribution $(2 \times 2 \mathrm{~cm})$. Time that took to break the film was recorded as the in vitro disintegration time..$^{20,35}$

\section{Solubility study}

The solubility of methylphenidate hydrochloride was determined in different types of solvent like water, methanol, ethanol, $0.1 \mathrm{~N}$ $\mathrm{HCl}$, chloroform, ethyl acetate, acetone, and $\mathrm{pH} 6.8$ phosphate buffer at room temperature. Saturated solutions were prepared by adding excess drug into the solvents to form a suspension and continued stirring for $24 \mathrm{~h}$ in the presence of drug particles. The saturated suspensions were filtered (using $0.2 \mu \mathrm{m}$ PTFE filters) to remove drug particles and the clear solutions were diluted to measure the drug concentration (Table 4).

\section{In vitro dissolution study}

The test was performed with a slight modification using the same method as mentioned by Dinge and Nagarsenker ${ }^{38}$ A film of $4 \mathrm{~cm}^{2}$ was placed in a glass petri dish and $25 \mathrm{~mL}$ of dissolution medium (phosphate-buffered saline $\mathrm{pH}$ 6.8) was added. A stirring speed of $100 \mathrm{rpm}$ was selected for the dissolution of the batches. An aliquot of $2.5 \mathrm{~mL}$ was withdrawn and replaced with equal volumes of $\mathrm{pH}$ buffer 6.8 at regular intervals of $1,2,3,4,5,7.5$, and 10 minutes to maintain sink condition. The collected samples were filtered through the Whatman filter and using a UV-visible spectrophotometer, the concentration of dissolved methylphenidate $\mathrm{HCl}$ was measured at the required wavelength. ${ }^{36-38}$

\section{Folding endurance}

Folding endurance was observed and determined by repeated folding of strip at the same place until strip broke due to folding. The number of times the film was folded without breaking was determined as the folding endurance value. . $^{39,40}$

Table 4. Solubility data of methylphenidate $\mathrm{HCl}$

\begin{tabular}{ll} 
Solvent & Solubility $(\mathrm{mg} / \mathrm{mL})$ \\
\hline Water & $>100$ \\
\hline Methanol & $>100$ \\
\hline Ethanol & $>25$ \\
\hline $0.1 \mathrm{~N} \mathrm{HCl}$ & $>100$ \\
\hline Chloroform & $>100$ \\
\hline Ethyl acetate & 0.08 \\
\hline Acetone & 0.9 \\
\hline Phosphate buffer pH 6.8 & $>100$ \\
\hline
\end{tabular}

\section{Stability study}

Stability testing's goal was to show how the consistency of a drug ingredient or drug product changes over time, when exposed to a range of environmental factors including temperature, humidity, and light, allowing for recommended storage conditions, retest times, and shelf-life. International Conference on Harmonization $(\mathrm{ICH})$ specifies the length of study and storage conditions. ${ }^{41-43}$

\section{Method}

The sample was wrapped in aluminum foil and subjected to stability studies as per the $\mathrm{ICH}$ guidelines. After that, they were held in a stability chamber at $40^{\circ} \mathrm{C} / 75^{\circ} \mathrm{F}$ for 3 months and tested for their physical appearance, drug quality, in vitro disintegration duration, and drug release at 1 month intervals with the findings being released. $41,43,44$

\section{Release kinetics and mechanisms}

Data obtained from dissolution studies were fitted to various kinetic equations. The kinetic models used were zero order (cumulative percentage of drug unreleased $v s$. time in min), the first order (log cumulative percentage of drug remaining vs. time), Hixon-Crowell model (M01/3-M1/3 vs. time in min), Higuchi's model (cumulative percentage of drug released vs. square root of time), and Korsmeyer-Peppas model (log cumulative percentage of drug released $v s$. log time) equation. These data are used to find $\mathrm{R}^{2}$ value.

\section{RESULTS AND DISCUSSION}

$\lambda_{\max }$ of the drug was determined by scanning $1000 \mu \mathrm{g} / \mathrm{mL}$ concentration solution prepared with $\mathrm{pH} 6.8$ buffer in range 200$400 \mathrm{~nm}$ using a double beam UV-visible spectrophotometer. $\lambda_{\max }$ was found to be $257.257 \mathrm{~nm}$ (Figure 1). Therefore, further studies were conducted in a wavelenght of $257.2 \mathrm{~nm}$.

Fourier-transform infrared spectroscopy (FTIR) and differential scanning calorimetry (DSC) studies

An FTIR spectrophotometer was used to conduct the compatibility tests. A $\mathrm{KBr}$ disc was used to investigate IR spectrum of a pure substance and a physical combination of drug and polymer..$^{45,46}$ In different samples, the distinctive peaks of methylphenidate hydrochloride were obtained at different wavenumbers (Figure 3, Table 5)

The spectra for all formulations are shown below.

In the above spectrum, the characteristic (principal) peaks of methylphenidate hydrochloride are presented as follows.

FTIR spectra of methylphenidate hydrochloride+ HPMC E5 (Figure 4) exhibited peaks at $711 \mathrm{~cm}^{-1}$ (monosubstituted benzene), $1593 \mathrm{~cm}^{-1}$ in the presence of (aromatic stretch), $2411-2681 \mathrm{~cm}^{-1}$ (secondary amine salt), $1756 \mathrm{~cm}^{-1}$ (C=O stretch), 1182-1201 cm (C-O stretch). Here, all the principal peaks are exhibited in the range. FTIR spectra of methylphenidate hydrochloride+ HPMC E15 (Figure 5) exhibited peaks at $699 \mathrm{~cm}^{-1}$ (monosubstituted benzene), $1592 \mathrm{~cm}^{-1}$ presence of (aromatic stretch), 2411$2588 \mathrm{~cm}^{-1}$ (secondary amine salt), $1745 \mathrm{~cm}^{-1}$ ( $C=0$ stretch), $1110-1210 \mathrm{~cm}^{-1}$ (C-O stretch). Here, all the principal peaks 
are exhibited in the range. FTIR spectra of methylphenidate hydrochloride+ maltodextrin (Figure 6) exhibited peaks at 701-721 $\mathrm{cm}^{-1}$ (monosubstituted benzene), $1592 \mathrm{~cm}^{-1}$ presence of (aromatic stretch), 2419-2633 $\mathrm{cm}^{-1}$ (secondary amine salt), $1734 \mathrm{~cm}^{-1}$ ( $\mathrm{C}=\mathrm{O}$ stretch), $1115-1145 \mathrm{~cm}^{-1}$ (C-O stretch). Here, all the principal peaks are exhibited in the range. FTIR spectra of MDF formulation (Figure 7) exhibited peaks at $713 \mathrm{~cm}^{-1}$ (monosubstituted benzene), $1595 \mathrm{~cm}^{-1}$ presence of (aromatic stretch), 2398-2511 cm-1 (secondary amine salt), $1731 \mathrm{~cm}^{-1}(\mathrm{C}=0$ stretch), $1141-1190 \mathrm{~cm}^{-1}$ (C-O stretch). Here, all the principal peaks exhibit in the range.

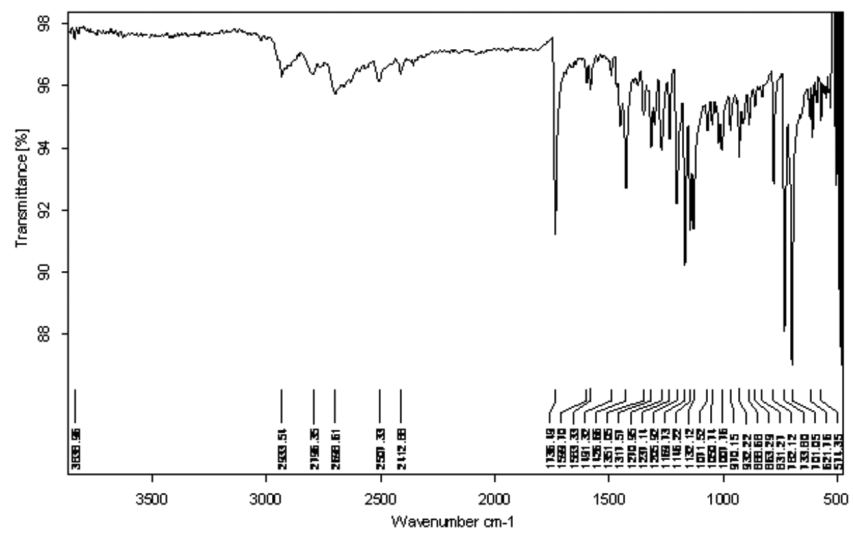

Figure 3. FTIR spectrum of pure methylphenidate hydrochloride

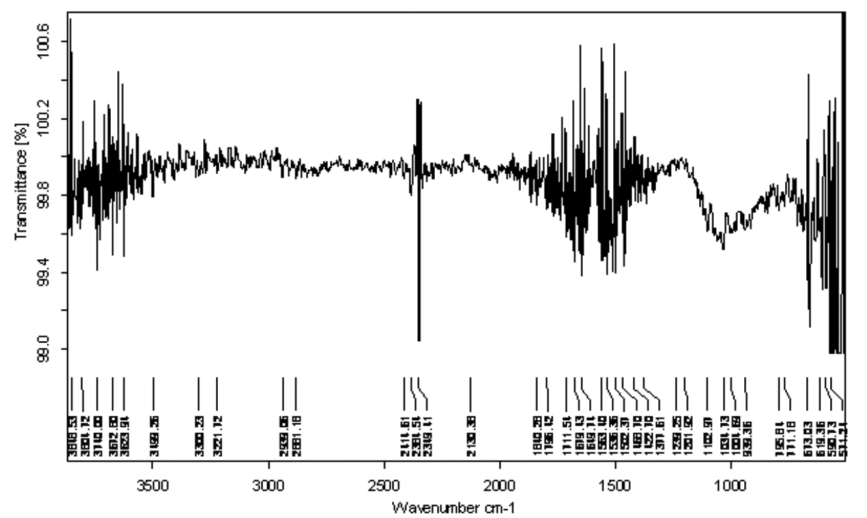

Figure 4. FTIR spectrum of methylphenidate $\mathrm{HCl}+\mathrm{HPMC}$ E5

\section{Table 5. FTIR characteristic (principal) spectral details}

\begin{tabular}{ll}
\hline Pure methylphenidate hydrochloride & Stretching \\
\hline 701,733 & Monosubstituted benzene \\
\hline 1599 & Aromatic stretch \\
\hline $2412-2698$ & Secondary amine salt \\
\hline 1736 & C=O stretch \\
\hline $1146-1169$ & C-O stretch \\
\hline
\end{tabular}

FTIR: Fourier-transform infrared spectroscopy
In the spectrum of the drug-polymer mixture, all the peaks are present and in the formulation. This indicates that there is no interaction between the drug and the formulation components.

\section{DSC}

DSC thermogram of methylphenidate hydrochloride showed an endothermic peak at $229.41^{\circ} \mathrm{C}$ corresponding to its melting

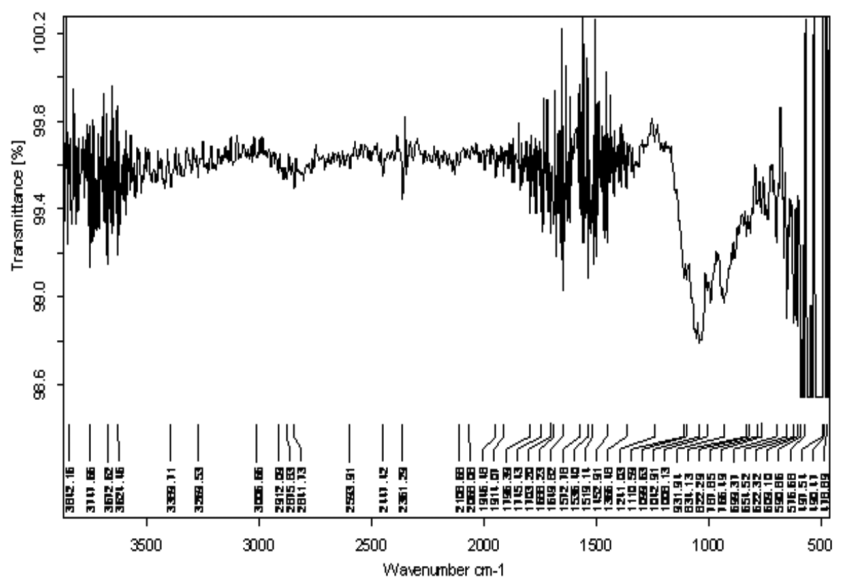

Figure 5. FTIR spectrum of methylphenidate $\mathrm{HCl}+\mathrm{HPMC}$ E15

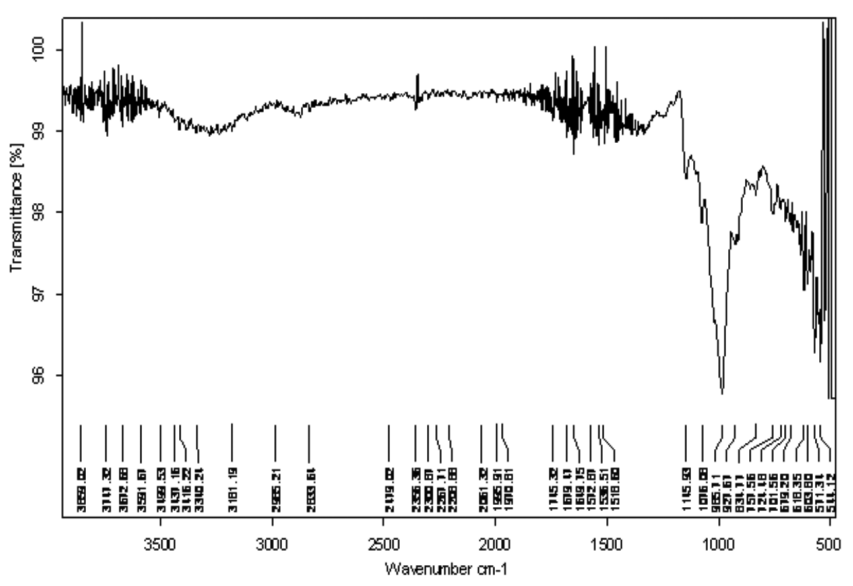

Figure 6. FTIR spectrum of methylphenidate $\mathrm{HCl}+$ maltodextrin

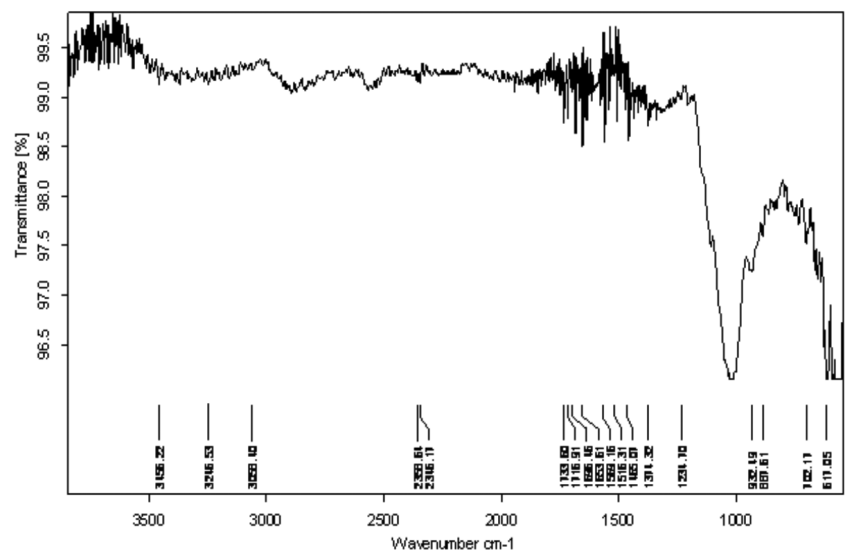

Figure 7. FTIR of mouth dissolving film formulation 
point. ${ }^{38}$ DSC thermograms of the drug with other excipients do not display a profound shift in peaks $\left(229.41^{\circ} \mathrm{C}\right)$, which indicates compatibility. DSC thermograms of the individual drug and final formulation are shown in Figure 8 and $9 .{ }^{47}$

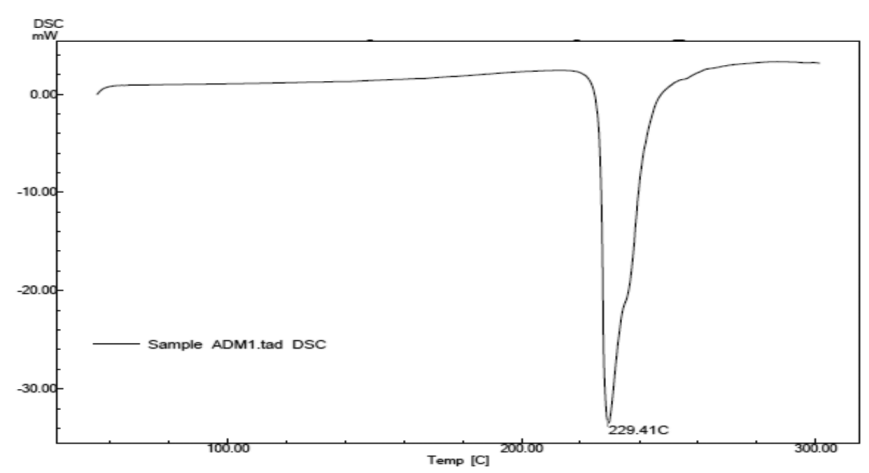

Figure 8. DSC of pure drug

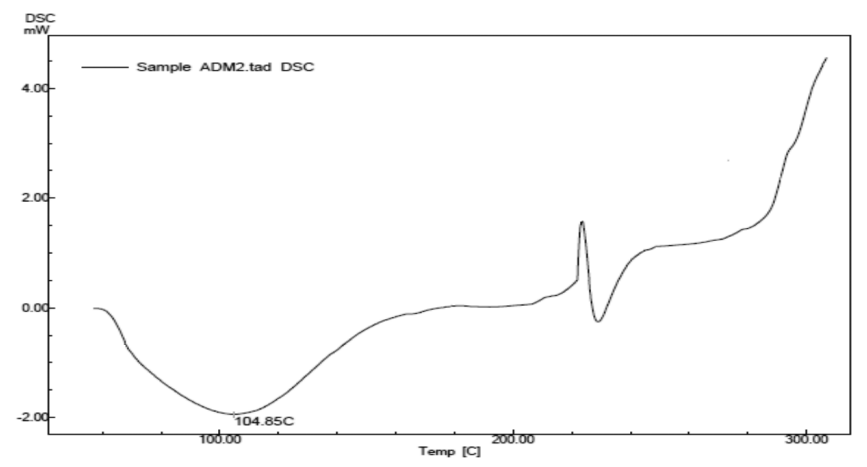

Figure 9. DSC of formulation

\section{Preliminary studies on the selection of polymers}

A preliminary research was conducted to identify appropriate polymers and a suitable plasticizer capable of manufacturing films with favorable mechanical properties and disintegration times. ${ }^{48}$ The solvent casting process was used to make the casting solution. The composition of various batches, number of polymers used, and their appearance and disintegration time are given in Table 6.

\section{Optimization of polymer}

Placebo films were prepared using maltodextrin, HPMC E3, HPMC E5, and HPMC E15 as film-forming agents in various amounts. The placebo films prepared using maltodextrin as a film former in various amounts of $750,1000,1250$, and 1500 mg were not having acceptable physical characteristics. The lowest amount of maltodextrin (PB1), when cast in the plastic petri dish having an area of $70 \mathrm{~cm}^{2}$, was insufficient for making the film. In other batches of maltodextrin (PB2 to PB4), amounts were sufficient for making the film, which was sticky. Thus, maltodextrin alone was not selected as the film-forming polymer.

HPMC is a hydrophilic polymer that is suitable for the MDF. Various grades of HPMC could make films that were very transparent and had excellent mechanical properties. Placebo films of different grades of HPMC E3, HPMC E5, and HPMC E15 were prepared to verify their film-forming capacity and suitability for MDF. From all HPMC batches, PB7 for HPMC E3, PB9 for HPMC E5, and PB11 for HPMC E15 were easily removed from the petri dish and had good acceptable physical characteristics and low disintegration time in accordance with other batches (Table 6).

Films prepared from single polymers (PB7, PB9, PB11) gave good results for disintegration time, but other properties were not so good, so, combinations of different grades of HPMC were

Table 6. Characteristics of placebo film prepared using different polymers

\begin{tabular}{|c|c|c|c|c|}
\hline Batch & Polymer & Amount (mg) & Remarks & Disintegration time* $(\mathrm{sec})$ \\
\hline PB2 & \multirow{3}{*}{ Maltodextrine } & 1000 & Sticky & - \\
\hline PB3 & & 1250 & Sticky & - \\
\hline PB4 & & 1500 & Very sticky & - \\
\hline PB6 & \multirow[t]{2}{*}{ HPMC E3 } & 750 & Good & $32 \pm 1.732$ \\
\hline PB7 & & 1000 & Very good & $44.67 \pm 1.527$ \\
\hline PB8 & \multirow[b]{2}{*}{ HPMC E5 } & 500 & Average & $38.67 \pm 2.081$ \\
\hline PB9 & & 750 & Very good & $42.67 \pm 0.577$ \\
\hline PB13 & HPMC E15 & 1000 & Average & $66 \pm 2.645$ \\
\hline
\end{tabular}

*Results are shown in mean \pm SD $(n=3), S D$ : Standard deviation, HPMC: Hydroxypropyl methyl cellulose 
taken, which exerted better results in terms of disintegration time, folding endurance, and tensile strength.

A combination of different grades of HPMC and maltodextrin was tried and as a result, films having a much smoother texture were obtained. The combination yielded smoother films with less disintegration time, and finally, among the preliminary batches, PB22 was shown to give the best results (Table 7). Therefore, a combination of HPMC E5, HPMC E15, and maltodextrin was selected as the film-forming combination for the current work. ${ }^{49,50}$

\section{Optimization of plasticizer}

The films were prepared using propylene glycol and glycerol as plasticizers in different amounts ranging from 0.25 to $1.25 \mathrm{~mL}$ (Table 8 ). The results indicated that, with the least amount of plasticizer, films were very brittle and with the highest amount of plasticizer, films could not be dried properly and peeling off the problem was observed. Amongst the prepared films, PB24, PB25, PB30, and PB31 were good but their disintegration time was much higher than PB29 because of more amount of plasticizer. Based on folding endurance, tensile strength, and disintegration time, $0.5 \mathrm{~mL}$ of propylene glycol was selected as the optimum amount of plasticizer. ${ }^{50,51}$

\section{Statistical analysis}

Simplex centroid design is a type of mixture design that is often used to modify formulation variables with the simple prerequisite of knowing how independent variables interact. Preliminary investigations of the process parameters revealed that factors such the amount of HPMC E5 $\left(X_{1}\right)$, amount of HPMC $E 15\left(X_{2}\right)$, and amount of maltodextrin $\left(X_{3}\right)$ showed a significant influence on the amount of drug dissolved in $2 \min \left(C P R Q_{2} ; R_{1}\right)$, disintegration time $\left(R_{2}\right)$ and tensile strength $\left(R_{3}\right)$ of the drugloaded fast dissolving film. As a result, it was used in further research. All three chosen dependent variables $\left(X_{1}, X_{2}\right.$, and $\left.X_{3}\right)$ showed large variance in disintegration time, volume of drug released in 2 minutes, and tensile strength for all 7 batches (Table 9). The data showed that $X_{1}, X_{2}$, and $X_{3}$ had a major effect on those responses $\left(R_{1}, R_{2}\right.$, and $\left.R_{3}\right)$. Since considering the magnitude of coefficients and statistical signals, polynomial equations can be used to determine, whether the response is positive or negative. The statistical analysis (ANOVA) results for the design batches are shown below. ${ }^{46,52}$

Table 7. Optimization of mixture of polymers

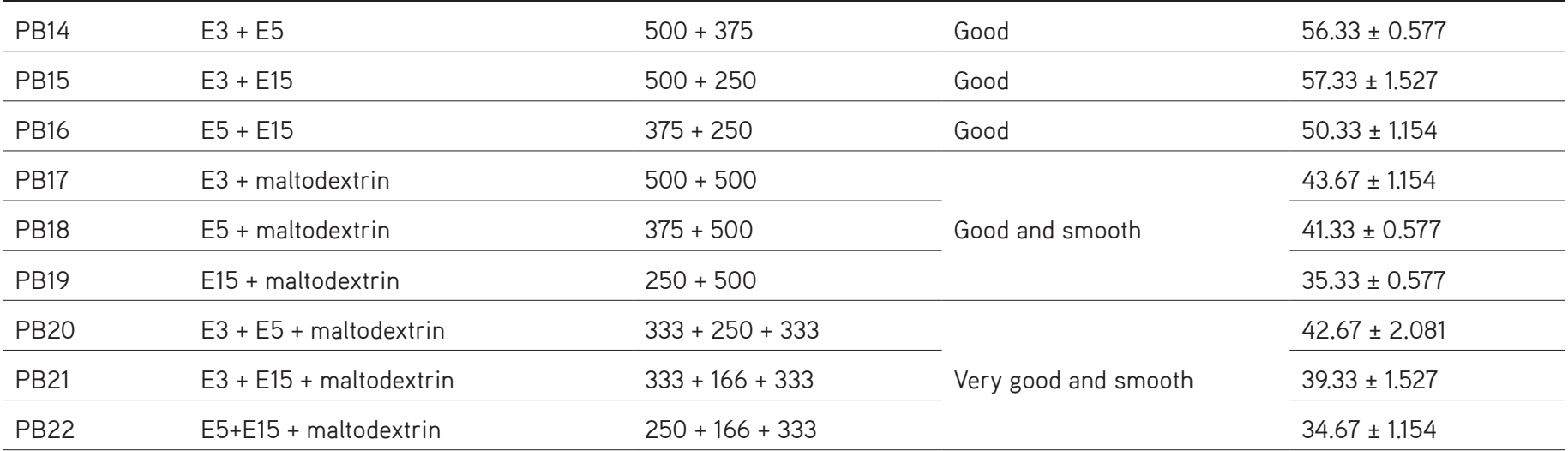

*Results are shown in mean \pm SD $(n=3)$, SD: Standard deviation

Table 8. Characteristics of placebo films prepared using different plasticizer

\begin{tabular}{|c|c|c|c|c|c|}
\hline Batch $^{\#}$ & Plasticizer & Amount (mL) & Folding endurance & Disintegration time* $(\mathrm{sec})$ & Tensile strength* $\left(\mathrm{n} / \mathrm{cm}^{2}\right)$ \\
\hline PB23 & \multirow{4}{*}{ Glycerin } & 0.25 & 142 & Brittle & - \\
\hline PB24 & & 0.5 & 156 & $66.33 \pm 2.081$ & $3.11 \pm 0.061$ \\
\hline PB25 & & 0.75 & - & $74.66 \pm 4.167$ & $3.18 \pm 0.017$ \\
\hline PB26 & & 1 & - & Peel off problem & - \\
\hline PB28 & \multirow{4}{*}{ Propylene glycol } & 0.25 & - & Brittle & - \\
\hline PB29 & & 0.5 & 148 & $46 \pm 1.73$ & $2.42 \pm 0.023$ \\
\hline PB30 & & 0.75 & 152 & $59.66 \pm 3.055$ & $2.74 \pm 0.068$ \\
\hline PB31 & & 1 & 156 & $64.33 \pm 2.516$ & $2.96 \pm 0.066$ \\
\hline
\end{tabular}

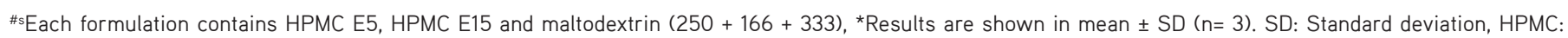
Hydroxypropyl methyl cellulose 
Response 1: $C P R Q_{2}\left(R_{1}\right)$

The magnitude of coefficients and mathematical signs can be used to determine whether the polynomial equations express positive or negative information. Statistical analysis was carried out in Design-Expert software (7.1.5), which suggested that a special cubic model (SCM) was followed for drug release $\%$ in 2 minutes with a $p$ value of 0.0385 . This indicated that the model was highly significant.

Polynomial equation

$R_{1}\left(C P R Q_{2}\right)=+104.21^{\star} A+86.83^{*} B+94.30 * C-9.16{ }^{*} A^{*} B+$ $8.62{ }^{*} A{ }^{*} C+23.53^{*} B{ }^{*} C+55.72{ }^{*} A{ }^{*}{ }^{*} C$

To determine contribution of each component and their interaction, an ANOVA for SCM was carried out.

The statistical analysis (ANOVA) results (Table 10), contour plot, and 3D surface plot for cumulative percentage release (CPR), $Q_{2}$ (Figure 10) presents a strong effect of three factors (amounts of HPMC E5, HPMC E15, and maltodextrin). A polynomial equation of $Q_{2}$ indicates that three polymer amounts have a positive effect on the $Q_{2}$. In vitro dissolution of the films increased with the increase in amount of the polymer. It was noted that, when the amounts of polymer were selected within the limits of the design, in vitro dissolution rate increased to a greater extent with the amount of HPMC E5 and increased to a lesser extent in the case of maltodextrin followed by HPMC E15. As per the equation, better release can be achieved with the combination of the three polymers, rather than combining any two of them. ${ }^{53}$

\section{Response 2: Disintegration time $\left(R_{2}\right)$}

Statistical analysis was carried out in Design-Expert software (7.1.5), which recommended that a SCM was followed for release at $\mathrm{T} 2{ }_{\text {min }}$ with a $p$ value of 0.0385 . This indicated that the model was highly significant. ${ }^{53}$

\section{Polynomial equation}

$R_{2}$ (disintegration time) $=+38.50 * A+78.00 * B+35.00 * C-$ $25.00 * A{ }^{*} B+37.00 * A{ }^{*} C+26.00 * B{ }^{*} C-235.50 * A{ }^{*} B{ }^{*} C$

To find the contribution of each component and their interaction, an ANOVA for SCM was carried out.

ANOVA results (Table 11), contour plot, and 3D surface plot for the disintegration time (Figure 11) indicates the strong effect of the three factors (amounts of HPMC E5, HPMC E15, and maltodextrin). A polynomial equation of disintegration time indicates that the three polymers amounts have a positive effect on the disintegration time. In vitro disintegration time of the films was observed to increase as the volume of polymer was increased. It was noticed that, when the amounts of polymer

Table 9. Design summary

\begin{tabular}{llll} 
Formulation code & $R_{1}$ & $R_{2}$ & $R_{3}$ \\
\cline { 2 - 3 } & $Q_{2 \min }{ }^{*}$ & Disintegration time $(\mathrm{sec})^{*}$ & Tensile strength $\left(\mathrm{n} / \mathrm{cm}^{2}\right)^{*}$ \\
\hline F1 & $104.44 \pm 2.91$ & $38 \pm 0.57$ & $2.7 \pm 0.02$ \\
\hline F2 & $97.08 \pm 2.89$ & $78 \pm 1.15$ & $3.43 \pm 0.06$ \\
\hline F3 & $99.80 \pm 0.80$ & $35 \pm 2.01$ & $2.39 \pm 0.03$ \\
\hline F4 & $98.12 \pm 1.62$ & $52 \pm 2.64$ & $3.1 \pm 0.07$ \\
\hline F5 & $101.41 \pm 1.89$ & $46 \pm 1.73$ & $2.52 \pm 0.01$ \\
\hline F6 & $98.86 \pm 3.18$ & $63 \pm 2.31$ & $2.94 \pm 0.04$ \\
\hline F7 & $99.73 \pm 1.78$ & $46 \pm 2.64$ & $2.84 \pm 0.02$ \\
\hline F1 (R) & $103.94 \pm 0.27$ & $39 \pm 1.52$ & $2.72 \pm 0.02$ \\
\hline
\end{tabular}

*Results are shown in mean $\pm S D(n=3), S D$ : Standard deviation, $R_{1}$ : Response $1, R_{2}$ : Response 2, $R_{3}$ : Response 3

Table 10. ANOVA for special cubic model (\% release at $2 \mathrm{~min}$ )

\begin{tabular}{|c|c|c|c|c|c|}
\hline Source & Sum of squares & DF & Mean square & $F$ value & Prob $>\mathrm{F}$ \\
\hline Model & 253.82 & 6 & 42.30 & 395.44 & 0.0385 \\
\hline Linear mixture & 210.05 & 2 & 105.02 & 981.76 & 0.0226 \\
\hline$A B$ & 3.81 & 1 & 3.81 & 35.62 & 0.1057 \\
\hline$A C$ & 3.38 & 1 & 3.38 & 31.60 & 0.1121 \\
\hline Pure error & 0.11 & 1 & 0.11 & - & - \\
\hline Cor total & 253.92 & 7 & - & - & - \\
\hline
\end{tabular}

DF: Degree of freedom 
were selected within the limits of the design, in vitro dissolution rate decreased the most, when more amounts of maltodextrin were used in the formulation, which increased gradually with HPMC E5 followed by HPMC E15. As per the equation, a shorter disintegration time can be achieved with the combination of the three polymers, rather than the single polymer or with the combination of any two of them.

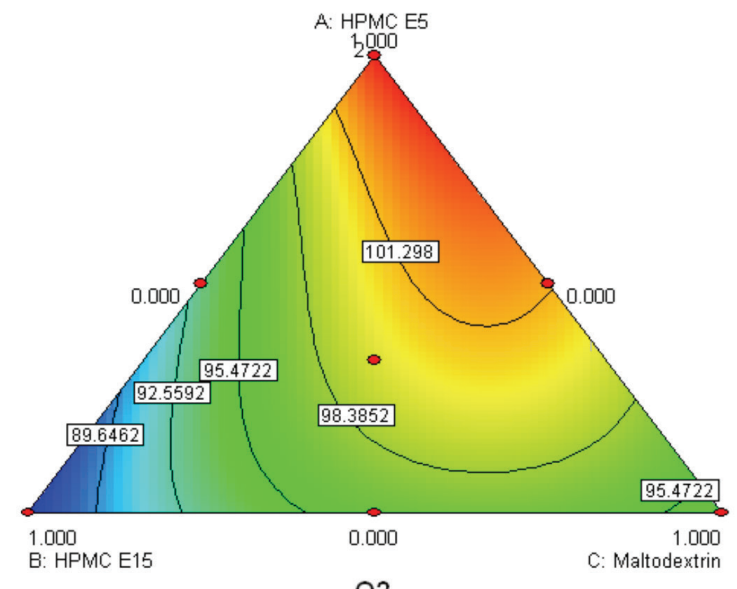

Q2

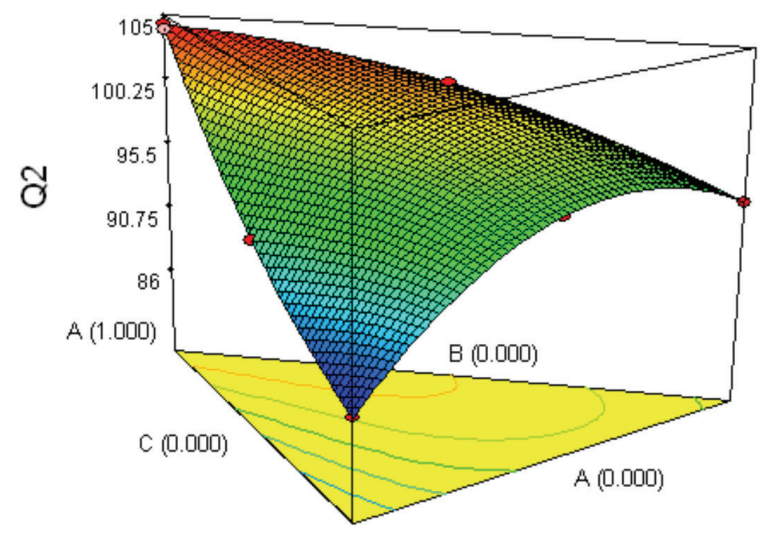

$B(1.000)$

Figure 10. Contour plot and $3 D$ surface plot of $C P R Q_{2}(\%)$ against amounts of HPMC E5, HPMC E15, and maltodextrin
Response 3: Tensile strength $\left(R_{3}\right)$

Statistical analysis was carried out in Design-Expert software (7.1.5), which suggested that SCM was followed for release at $\mathrm{T} 2{ }_{\text {min }}$ with a $p$ value of 0.0385 . It revealed that the model was highly significant.

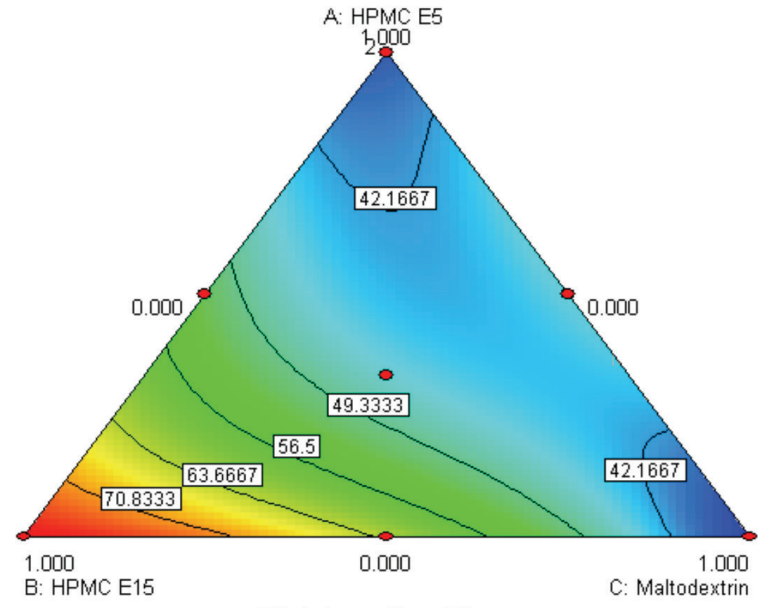

Disintegration Time

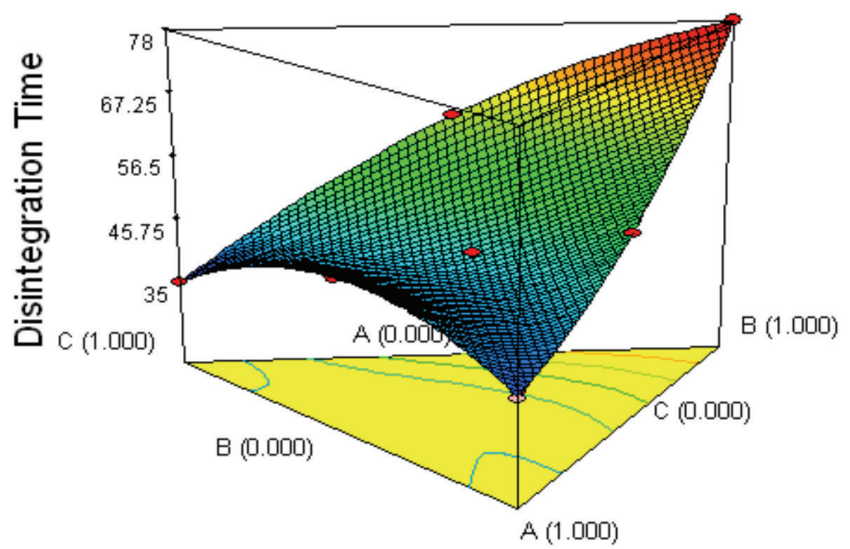

Figure 11. Contour plot and 3D surface plot of disintegration time (seconds) against amounts of HPMC E5, HPMC, E15, and maltodextrin

\section{Table 11. ANOVA for special cubic model (disintegration time)}

\begin{tabular}{llllll} 
Source & Sum of squares & DF & Mean square & F value & Prob $>$ F \\
\hline Model & 1477.38 & 6 & 246.23 & 492.46 & 0.0345 \\
\hline Linear mixture & 1320.95 & 2 & 660.48 & 1320.95 & 0.0195 \\
\hline AB & 28.41 & 1 & 28.41 & 56.82 & 124.45 \\
\hline AC & 62.23 & 1 & 62.23 & 56.33 & 0.0569 \\
\hline BC & 28.17 & 1 & 28.17 & 93.72 & 0.0843 \\
\hline ABC & 46.86 & 1 & 46.86 & - & - \\
\hline Pure error & 0.50 & 1 & 0.50 & - & - \\
\hline Core total & 1477.88 & 7 & - &
\end{tabular}

DF: Degree of freedom 


\section{Polynomial equation}

$R_{3}$ (tensile strength) $=+2.71^{\star} A+3.43^{\star} B+2.39^{\star} C+0.15^{\star} A{ }^{\star} B-$ $0.1{ }^{\star} A{ }^{\star} C+0.12{ }^{\star} B^{\star} C-0.45^{\star} A{ }^{\star} B^{\star} C$

To determine impact of each component and their interaction, ANOVA for SCM was carried out. The ANOVA results (Table 12),

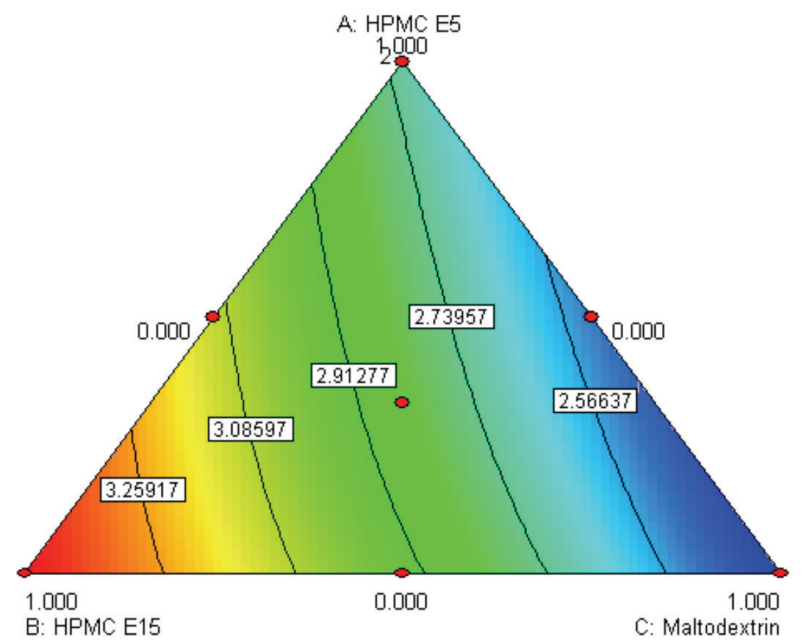

Tensile Strenght

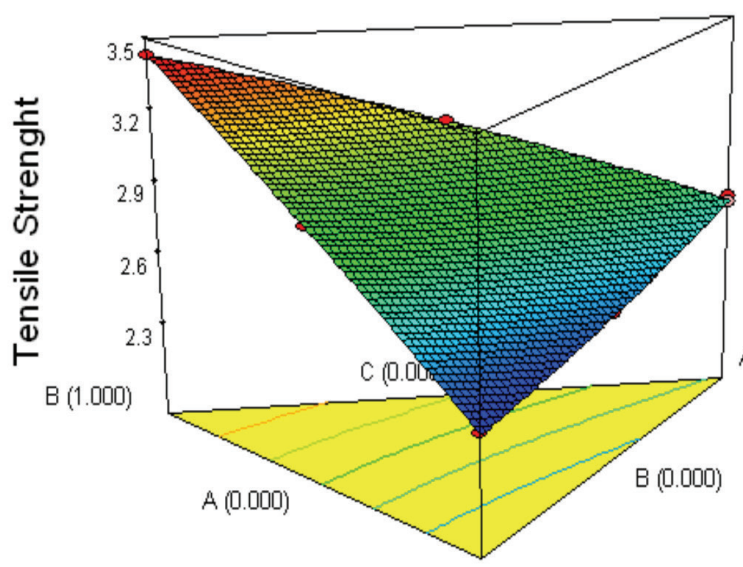

Figure 12. Contour plot and 3D surface plot of tensile strength $\left(\mathrm{n} / \mathrm{cm}^{2}\right)$ against amounts of HPMC E5, HPMC, E15 and maltodextrin
3D surface plot, and contour plot for the tensile strength (Figure 12 ) indicated the strong effect of the three factors (amounts of HPMC E5, HPMC E15, and maltodextrin). A polynomial equation of tensile strength indicates that all the all the three-polymer amount have a positive effect on the tensile strength. It was observed that when the amounts of polymer were selected within the limits of the design, tensile strength was increased when more amounts of HPMC E15 were used in the formulation and it increased to a lesser extent in HPMC E5 followed by maltodextrin. As per the equation, values of tensile strength were decreased with the combination of all three polymers. ${ }^{53,54}$

\section{Evaluation parameters for film formulation}

\section{Weight variation tests}

Table 13 summarizes weight difference $\%$ for all formulations. They were under the pharmacopeial limits of $7.5 \%$, so both of the films passed weight variation test. It was found to be in the range of $37 \pm 2.081$ to $81.67 \pm 2.081 \mathrm{mg}$. Films having more amount of maltodextrin exhibited higher weight, whereas films having HPMC E5 were lighter in weight. Weight of the films was uniform. ${ }^{55}$

\section{Thickness}

The formulated films were observed to have thicknesses ranging from $0.103 \pm 0.015$ to $0.207 \pm 0.02 \mathrm{~mm}$. Table 13 lists the mean values. In both formulations, the values are almost identical. Films containing maltodextrin resulted in increased thickness, which was required for comfortable handling of the film. ${ }^{56}$

\section{Folding endurance}

The films' folding endurance was measured by folding a small strip of film at the same location before it separated and the average folding endurance of all films is shown in Table 13. All the batches have folding endurance of $101 \pm 2.645$ to $177.67 \pm$ 3.51. The folding endurance increases as concentration of the polymer increases. . $^{57,58}$

\section{Drug content}

Drug content and uniformity tests were carried out to ensure that the drug was distributed uniformly and accurately. The content uniformity of all nine formulations was determined, where the

Table 12. ANOVA for special cubic model (tensile strength)

\begin{tabular}{|c|c|c|c|c|c|}
\hline Source & Sum of squares & DF & Mean square & $\mathrm{F}$ value & Prob $>\mathrm{F}$ \\
\hline Model & 0.77 & 6 & 0.13 & 450.86 & 0.0360 \\
\hline Linear mixture & 0.76 & 2 & 0.38 & 1348.51 & 0.0193 \\
\hline $\mathrm{AC}$ & 5.767E-004 & 1 & 5.767E-004 & 2.04 & 0.3889 \\
\hline $\mathrm{BC}$ & 5.709E-004 & 1 & 5.709E-004 & 2.02 & 0.3905 \\
\hline Pure error & $2.828 \mathrm{E}-004$ & 1 & $2.828 \mathrm{E}-004$ & - & - \\
\hline Cor total & 0.77 & 7 & - & - & - \\
\hline
\end{tabular}

DF: Degree of freedom 
results are listed in Table 13. A spectrophotometer was used to examine three trials for each formulation. Mean values of all the formulations and SDs were calculated. The findings showed that both formulations had the same drug material. In in vitro release trials, the total \% of drug released from each film was calculated using the mean quality of the drug contained in the film. Ranges of drug content in the formulations were $95.218 \%$ to $98.00 \% .^{58}$

\section{In vitro dissolution study}

In vitro release studies of methylphenidate hydrochloride films were performed in phosphate buffer ( $\mathrm{pH}$ 6.8). Cumulative drug release was calculated based on the drug content of methylphenidate hydrochloride. Rapid drug dissolution was observed in F1, F5, which released $104.44 \%$ and $101.41 \%$, respectively, at the end of 2 min. Comparatively, slow drug dissolution was observed in F6, F7 with the release of $96.45 \%$ and $99.73 \%$, respectively. At end of 2 min, remaining formulations had slower drug release than the above-mentioned formulations. As the concentration of polymer HPMC E15 increased, the time for drug release was found to be increasing. This might be due to the higher viscosity of the polymer, which results in the formation of a strong matrix layer decreasing mobility of drug particles in swollen matrices, which leads to a delay in drug release. ${ }^{36}$

Table 14 shows the data of dissolution of prepared design batches. Figure 13 shows the graph of CPR versus time in minutes. The data indicated the data up to 2 min only, so that, we can easily compare the dissolution and \% of drug release within our desired time limit. From Figure 13, we may conclude that in the first minute, drug release for every batch is almost the same, but for the consecutive minutes, number of drug release changes. So, we may say that polymers having a lower viscosity release the drug quickly than the polymers with higher viscosity. Thus, in order to get a quicker release, lower viscosity-grade polymers are desirable. ${ }^{47}$

\section{Optimized batch analysis by statistical analysis}

The optimized formulation was chosen based on criteria, a higher amount of drug release in 2 minutes, shortest disintegration time, and a medium value of tensile strength.
Overlay plot was drawn to obtain an optimized batch using Design Expert (7.1.5) (Figure 14).

An optimized batch of the film was prepared experimentally using the same procedure/the results of stated parameters were compared with the computed values from regression equations. When the experimental and theoretical values were compared, error \% was found to be less than $8 \%$ for the responses (Table 15).

\section{Stability studies}

A stability study was conducted according to the $\mathrm{ICH}$ guidelines for a short time. The developed formulations were tested for stability at $40^{\circ} \mathrm{C}$ and $75 \%$ relative humidity for 6 months and were evaluated for tensile strength, disintegration time, and in vitro drug release at 1,3 , and 6 month intervals. Effects of the formulations were deemed within acceptable limits as seen in Table 16. The measurable parameters showed no major differences. So, the formulation was found to be stable. ${ }^{47}$

\section{Release kinetics and mechanisms}

Data of in vitro release were fit into different equations and kinetic models to explain release kinetics of methylphenidate from these films. Release kinetics of methylphenidate followed zero order from the films (Table 17). A better fit (highest $\mathrm{R}^{2}$ values) was observed in the case of Higuchi's model than HixonCrowel model except film I. Hence, mechanism of drug release

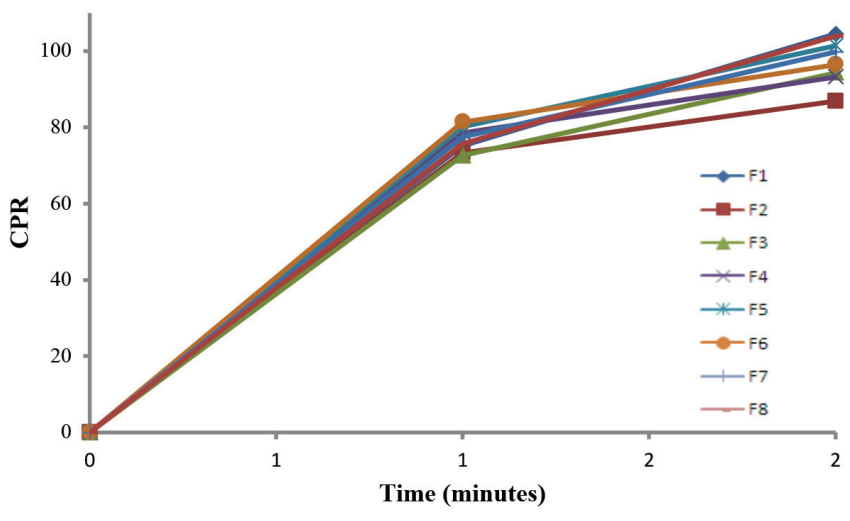

Figure 13. In vitro release of methylphenidate hydrochloride in phosphate buffer ( $\mathrm{pH}$ 6.8) from the film formulation

Table 13. Evaluation parameters of experimental design batches

\begin{tabular}{lllll} 
Batches & Weight variation $\pm \mathrm{SD}^{*}(\mathrm{mg})$ & Thickness $\pm \mathrm{SD}^{*}(\mathrm{~mm})$ & Folding endurance $\pm \mathrm{SD}^{*}$ & Drug content $\pm \mathrm{SD}^{*}(\%)$ \\
\hline $\mathrm{F} 1$ & $37.33 \pm 2.081$ & $0.117 \pm 0.011$ & $108 \pm 3.51$ & $95.21 \pm 0.52$ \\
\hline $\mathrm{F} 2$ & $72.66 \pm 1.527$ & $0.167 \pm 0.005$ & $101 \pm 2.645$ & $95.41 \pm 0.63$ \\
\hline $\mathrm{F} 3$ & $81.67 \pm 2.081$ & $0.207 \pm 0.02$ & $116 \pm 3.05$ & $96.41 \pm 0.46$ \\
\hline F4 & $54.33 \pm 1.527$ & $0.137 \pm 0.011$ & $103 \pm 2.0$ & $98.00 \pm 0.87$ \\
\hline F5 & $80.33 \pm 2.081$ & $0.17 \pm 0.02$ & $117.67 \pm 4.15$ & $95.41 \pm 0.56$ \\
\hline F6 & $76.33 \pm 2.301$ & $0.103 \pm 0.015$ & $109 \pm 5.03$ & $97.40 \pm 0.58$ \\
\hline F7 & $62.66 \pm 1.527$ & $0.133 \pm 0.011$ & $115 \pm 5.291$ & $96.01 \pm 0.48$ \\
\hline F1 (R) & $37.66 \pm 2.31$ & $0.17 \pm 0.10$ & $108 \pm 3.60$ & $95.41 \pm 0.52$ \\
\hline
\end{tabular}

${ }^{*}$ All results are shown in mean $\pm \operatorname{SD}(n=3), S D$ : Standard deviation 
from the remaining films followed is diffusion controlled and drug release from film I followed dissolution controlled (Table 18).

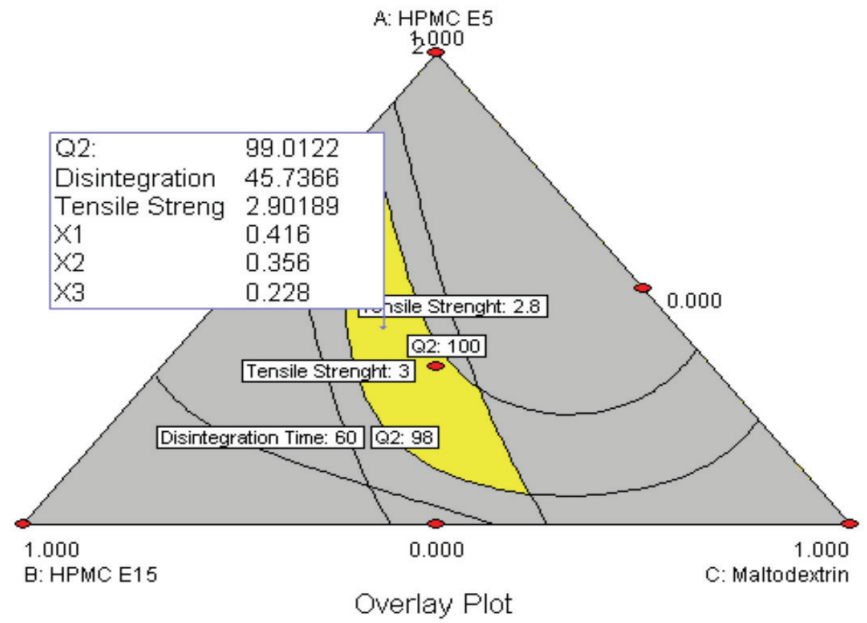

Figure 14. Overlay plot

Table 14. Cumulative $\%$ of drug release from film formulations

\begin{tabular}{llllll} 
Time (min) & 0 & 1 & 2 & 3 & 4 \\
\hline F1 & $0.0 \pm 0.0$ & $75.19 \pm 2.30$ & $104.44 \pm 2.91$ & - & - \\
\hline F2 & $0.0 \pm 0.0$ & $73.34 \pm 1.04$ & $86.83 \pm 1.00$ & $89.64 \pm 3.40$ & $97.08 \pm 2.89$ \\
\hline F3 & $0.0 \pm 0.0$ & $72.62 \pm 3.88$ & $94.30 \pm 2.04$ & $99.80 \pm 0.80$ & - \\
\hline F4 & $0.0 \pm 0.0$ & $78.60 \pm 2.98$ & $93.23 \pm 2.02$ & $98.12 \pm 1.62$ & - \\
\hline F5 & $0.0 \pm 0.0$ & $80.12 \pm 2.27$ & $101.41 \pm 1.89$ & - & - \\
\hline F6 & $0.0 \pm 0.0$ & $81.40 \pm 2.53$ & $96.45 \pm 2.81$ & $98.86 \pm 3.18$ & - \\
\hline F7 & $0.0 \pm 0.0$ & $77.46 \pm 1.42$ & $99.73 \pm 1.78$ & - & - \\
\hline F1 (R) & $0.0 \pm 0.0$ & $75.74 \pm 0.378$ & $103.94 \pm 0.27$ & - & -
\end{tabular}

*All results are shown in mean \pm SD $(n=3), S D$ : Standard deviation

Table 15. Evaluation of optimized batch

\begin{tabular}{llll} 
Responses & Predicted value & Experimental value* & Relative error (\%) \\
\hline$Q_{2 \text { min }}$ & 99.01 & $98.45 \pm 0.99$ & -0.56 \\
\hline Disintegration time (sec) & 45.73 & $49 \pm 3$ & 7.15 \\
\hline Tensile strength $\left(\mathrm{n} / \mathrm{mm}^{2}\right)$ & 2.90 & $2.98 \pm 0.14$ & 2.75 \\
\hline
\end{tabular}

*All results are shown in mean \pm SD $(n=3), S D$ : Standard deviation

Table 16. Results of accelerated stability studies

\begin{tabular}{|c|c|c|c|c|}
\hline \multirow{2}{*}{ Evaluation parameters } & \multicolumn{4}{|c|}{ Time period for sampling* } \\
\hline & Initial & After 1 month & After 3 months & After 6 months \\
\hline $\mathrm{CPR}$ at $2 \min (\%)$ & $98.45 \pm 0.99$ & $98.06 \pm 5.44$ & $98.15 \pm 4.78$ & $98.42 \pm 2.35$ \\
\hline Disintegration time (sec) & $49 \pm 3$ & $47 \pm 1$ & $48 \pm 0.57$ & $49 \pm 0.57$ \\
\hline Tensile strength $\left(\mathrm{n} / \mathrm{cm}^{2}\right)$ & $2.98 \pm 0.14$ & $2.95 \pm 0.081$ & $3.01 \pm 0.07$ & $2.99 \pm 0.14$ \\
\hline
\end{tabular}

*All results are shown in mean \pm SD $(n=3), S D$ : Standard deviation

CPR: Cumulative percentage release
Application of the Hixon-Crowell cube root law, the equation $(\mathrm{M} 01 / 3-\mathrm{M} 1 / 3)=\mathrm{kt}$, provides information about the release mechanism, namely the dissolution rate limited. Application of Higuchi's equation $\left(M=K t_{1 / 2}\right)$ provides information about the release mechanism, namely the diffusion rate limited. Korsmeyer-Peppas model indicates that the release mechanism is not well-known or that more than one type of release phenomenon could be involved. The " $n$ " value could be used to characterize different release mechanisms (Table 19).

$\mathrm{R}^{2}$ values are higher for Higuchi's model compared to HixonCrowell for the films except film I. Hence, drug release from film I followed a dissolution rate-controlled mechanism and drug release from the remaining films followed a diffusion ratecontrolled mechanism.

According to the Korsmeyer-Peppas model, a value of slope between 0.5 and 1 indicates an anomalous behavior (nonFickian). So, it indicates that the release mechanism from the films follows non-Fickian diffusion (anomalous behaviour). However, film I follows case II transport. 
Table 17. Comparison of orders of in vitro release from all the patches

In vitro release in phosphate buffer $\mathrm{pH} 6.8$

Batches Regression equations

\begin{tabular}{lll} 
& Zero order & First order \\
\hline \multirow{2}{*}{ II } & $y=-1.6731 x+90.129$ & Log $y=-0.0227 x+2.1477$ \\
& $R^{2}=0.9799$ & $R^{2}=0.8944$ \\
\hline III & $y=-1.1987 x+86.842$ & Log $y=-0.0247 x+2.2969$ \\
& $R^{2}=0.9817$ & $R^{2}=0.6074$ \\
\hline \multirow{2}{*}{ IV } & $y=-0.8962 x+96.53$ & Log $y=-0.014 x+2.2549$ \\
& $R^{2}=0.9944$ & $R^{2}=0.6323$ \\
V & $y=-1.0745 x+93.923$ & Log $y=-0.0166 x+2.223$ \\
& $R^{2}=0.9933$ & $R^{2}=0.6606$ \\
VI & $y=-1.356 x+91.964$ & $\log y=-0.0236 x+2.2586$ \\
\hline \multirow{2}{*}{ VII } & $R^{2}=0.9921$ & $R^{2}=0.6991$ \\
\hline
\end{tabular}

Table 18. Comparison of regression equations of in vitro release from all the patches

\begin{tabular}{|c|c|c|c|}
\hline \multirow{2}{*}{ Batch } & \multicolumn{3}{|c|}{ In vitro release of drug in phosphate buffer $\mathrm{pH} 6.8$} \\
\hline & Hixon-Crowell model & Higuchi's model & Korsmeyer-Peppas model \\
\hline I & $\begin{array}{l}y=0.0159 x-0.0399 \\
R^{2}=0.9762\end{array}$ & $\begin{array}{l}y=13.552 x-11.116 \\
R^{2}=0.9744\end{array}$ & $\begin{array}{l}y=1.0295 x+0.255 \\
R^{2}=0.9464\end{array}$ \\
\hline ॥ & $\begin{array}{l}y=0.014 x-0.0571 \\
R^{2}=0.8862\end{array}$ & $\begin{array}{l}y=11.717 x-8.1596 \\
R^{2}=0.9733\end{array}$ & $\begin{array}{l}y=0.9141+0.3521 \\
R^{2}=0.9074\end{array}$ \\
\hline III & $\begin{array}{l}y=0.0092 x-0.0988 \\
R^{2}=0.8606\end{array}$ & $\begin{array}{l}y=10.24 x-18.435 \\
R^{2}=0.9239\end{array}$ & $\begin{array}{l}y=0.8815 x+0.2008 \\
R^{2}=0.9688\end{array}$ \\
\hline IV & $\begin{array}{l}y=0.0111 x-0.0775 \\
R^{2}=0.8668\end{array}$ & $\begin{array}{l}y=11.012 x-14.728 \\
R^{2}=0.9397\end{array}$ & $\begin{array}{l}y=0.9136 x-0.2446 \\
R^{2}=0.9561\end{array}$ \\
\hline V & $\begin{array}{l}y=0.0149 x-0.0777 \\
R^{2}=0.9094\end{array}$ & $\begin{array}{l}y=12.606 x-13.274 \\
R^{2}=0.9624\end{array}$ & $\begin{array}{l}y=0.979 x+0.2519 \\
R^{2}=0.9524\end{array}$ \\
\hline $\mathrm{VI}$ & $\begin{array}{l}y=0.0261 x-0.0411 \\
R^{2}=0.9662\end{array}$ & $\begin{array}{l}y=12.255 x-12.111 \\
R^{2}=0.9777\end{array}$ & $\begin{array}{l}y=0.9812 x+0.522 \\
R^{2}=0.9644\end{array}$ \\
\hline VII & $\begin{array}{l}y=0.012 x-0.0617 \\
R^{2}=0.9288\end{array}$ & $\begin{array}{l}y=11.177 x-9.634 \\
R^{2}=0.9755\end{array}$ & $\begin{array}{l}y=0.9144+0.5312 \\
R^{2}=0.9047\end{array}$ \\
\hline
\end{tabular}

Table 19. Slope of Korsmeyer-Peppas equation and proposed release mechanisms

\begin{tabular}{ll} 
Slope $(n)$ & Mechanism \\
\hline$<0.5$ & Fickian diffusion (Higuchi matrix) \\
\hline $0.5<n<1$ & Non-Fickian diffusion \\
\hline 1 & Case II transport \\
\hline
\end{tabular}

\section{CONCLUSION}

The prepared film of methylphenidate hydrochloride obtained using the solvent casting method showed the desired \% drug release, disintegration time, and tensile strength. The prepared film had a very smooth surface because of maltodextrin and without any interactions between the drug and polymer. The optimization of the film was done by simplex centroid design. The multiple regression analysis of the results led to equations that adequately describe the influence of the selected variables on the responses under study. Formulations with a \% drug release of more than $95 \%$ within 2 minutes were found in a specific region containing more amounts of HPMC E5 resulting in quicker drug release. Formulations with in vitro disintegration time $<60 \mathrm{sec}$ were found in a specific region containing high levels of HPMC E5 and maltodextrin and low levels of HPMC E15. The desired level of tensile strength was achieved, when the optimum amount of HPMC E15 was present in the film. High drug release $\%$ of the film in simulated saliva ( $\mathrm{pH}$ buffer 6.8) indicated that it could be helpful for treating acute ADHD and narcolepsy, where quick bioavailability of the drug is desired. 
Therefore, all designed batches were prepared and their evaluations were carried out which showing acceptable results. Based on the results, we may conclude that aim of the current work was successfully fulfilled.

\section{ACKNOWLEDGMENTS}

We would like to thank Ipca Laboratories Ltd. Mumbai, India, for giving us free samples of methylphenidate hydrochloride. We are also thankful to Colorcon Asia Pvt. Ltd. Goa, India, for the free sample of different HPMC grade and thankful to Saurashtra University, Rajkot, for providing me with facility of IR. We are also thankful to Atmiya Institute of Pharmacy, Rajkot, for providing us with facility for conducting the project successfully.

\section{Ethics}

Ethics Committee Approval: There is no requirement for ethical approval.

Informed Consent: Not applicable.

Peer-review: Externally peer-reviewed.

\section{Authorship Contributions}

Concept: B.B., Design: B.B., Data Collection or Processing: B.B., A.M., A.D., Analysis or Interpretation: B.B., A.M., A.D., Literature Search: A.M., A.D., Writing: B.B.

Conflict of Interest: No conflict of interest was declared by the authors.

Financial Disclosure: The authors declared that this study received no financial support.

\section{REFERENCES}

1. Arun A, Amrish C, Vijay S, Kamla P. Fast dissolving oral films: an innovative drug delivery system and dosage form. Int $\mathrm{J}$ ChemTech Res. 2010;2:576-583.

2. Basu B, Garala K, T J. Formulation and evaluation of pimozide buccal mucoadhesive patches. Res J Pharm Technol. 2018;11:4892-4898.

3. Boateng JS, Matthews KH, Auffret AD, Humphrey MJ, Eccleston GM, Stevens HN. Comparison of the in vitro release characteristics of mucosal freeze-dried wafers and solvent-cast films containing an insoluble drug. Drug Dev Ind Pharm. 2012;38:47-54.

4. Chinwala M. Recent formulation advances and therapeutic usefulness of orally disintegrating tablets (ODTs). Pharmacy (Basel). 2020;8:186.

5. Patel AR, Prajapati DS, Raval JA. Fast dissolving films (FDFs) as a newer venture in fast dissolving dosage forms. Int J Drug Dev Res. 2010;2:232246.

6. Maheswari KM, Devineni PK, Deekonda S, Shaik S, Uppala NP, Nalluri BN. Development and evaluation of mouth dissolving films of amlodipine besylate for enhanced therapeutic efficacy. J Pharm (Cairo). 2014;2014:520949.

7. Mahajan A. Formulation \& evaluation of fast dissolving buccal films of sertraline. Int. J. Drug Dev. Res. 2010;.4:220-226.

8. Ghorwade V, Patil A, Patil S, Ikkurthi K. Formulation and evaluation of Montelukast sodium fast dissolving films by using gelatin as a film base. Res. J. Pharm. Biol. Chem. Sci. 2011;2:880-888.
9. Koland M, Sandeep VP, Charyulu RN, Subrahmanyam EVS. The design and characterization of sublingual films of ondansetron hydrochloride. Int J Chem Sci. 2009;7:2927-2938.

10. Huss M, Duhan P, Gandhi P, Chen CW, Spannhuth C, Kumar V. Methylphenidate dose optimization for ADHD treatment: review of safety, efficacy, and clinical necessity. Neuropsychiatr Dis Treat. 2017;13:17411751.

11. Shelke PV, Dumbare AS, Gadhave MV, Jadhav SL, Sonawane AA, Gaikwad DD. Formulation and evaluation of rapidly dis integrating film of amlodipine besylate. J Drug Deliv Ther. 2010;2:72-75.

12. Woertz K, Tissen C, Kleinebudde P, Breitkreutz J. A comparative study on two electronic tongues for pharmaceutical formulation development. J Pharm Biomed Anal. 2011;55:272-281.

13. Patel R, Shardul N, Patel J, Baria A. Formulation development and evaluation of mouth melting film of ondansetron. Arch Pharm Sci Res. 2009;1:212-217.

14. Irfan M, Rabel S, Bukhtar Q, Qadir MI, Jabeen F, Khan A. Orally disintegrating films: a modern expansion in drug delivery system. Saudi Pharm J. 2016;24:537-546.

15. Kalyan S, Bansal M. Recent trends in the development of oral dissolving film. Int J PharmTech Res. 2010;4:725-733.

16. Meghana R, Velraj M. An overview on mouth dissolving film. Asian J Pharm Clin Res. 2018;11: 44-47.

17. Shimoda H, Taniguchi K, Nishimura M, Matsuura K, Tsukioka T, Yamashita H, Inagaki N, Hirano K, Yamamoto M, Kinosada Y, Itoh Y. Preparation of a fast dissolving oral thin film containing dexamethasone: a possible application to antiemesis during cancer chemotherapy. Eur J Pharm Biopharm. 2009;73:361-365.

18. Kumar V, Zakır F, Agarwal G, Choudhary A. Formulation and evaluation of buccal patches of venlafaxine. Int J Pharm Biol Sci. 2011;1:170-182.

19. Chaurasia G. A review on pharmaceutical preformulation studies in formulation studies in formulation and development of new drug molecules. Int J Pharm Sci. 2016;7:2313-2320.

20. Mishra R, Amin A. Formulation and characterization of rapidly dissolving films of cetirizine hydrochloride using pullulan as a film forming agent. Indian J Pharm Educ. 2011;45:71-77.

21. Patel JG, Modi AD. Formulation, optimization and evaluation of levocetirizine dihyrochloride oral thin strip. J Pharm Bioallied Sci. 2012;4(Suppl 1):S35-S36.

22. Khairnar A, Jain P, Baviskar D, Jain D. Developmement of mucoadhesive buccal patch containing aceclofenac: in vitro evaluations. Int J PharmTech Res. 2009;1:978-981.

23. Jadhav SD, Kalambe RN, Jadhav CM, Tekade BW, Patil VR. Formulation and evaluation of fast dissolving oral film of levocetirizine dihydrochlorid. Int J Pharm Sci. 2012;7:95-99.

24. Khan S, Shahi S, Borde S, Shaikh S. Formulation and evaluation of methylphenidate hydrochloride fast dissolving tablet by $\mathrm{QbD}$ approach. Asian J Pharm Clin. Res. 2018;5:33-42.

25. Bhupinder B, Sarita J. Formulation and evaluation of fast dissolving sublingual films of rizatriptan benzoate. Int J Drug Develop Res. 2012;4:133-143.

26. Kaity S, Maiti S, Ghosh AK, Pal D, Ghosh A, Banerjee S. Microsponges: a novel strategy for drug delivery system. J Adv Pharm Technol Res. 2010;1:283-290. 
27. Choudhary DR, Patel V, Patel H, Kundawala AJ. Exploration of film forming properties of film formers used in the formulation of rapid dissolving films. Int J Chem Tech Res. 2011;3:531-533.

28. Cilurzo F, Cupone IE, Minghetti P, Buratti S, Selmin F, Gennari CG, Montanari L. Nicotine fast dissolving films made of maltodextrins: a feasibility study. AAPS PharmSciTech. 2010;11:1511-1517.

29. Jyoti A, Singh G, Seema S, Rana AC. Fast dissolving films: a novel approach to oral drug delivery. Int Res J Pharm. 2011;2:69-74.

30. Kulkarni AS, Deakule HA, Mane MS, Ghadge DM. Exploration of different polymers for use in the formulation of oral fast dissolving strips. J Curr Pharm Res. 2010;33-35.

31. Dixit RP, Puthli SP. Oral strip technology: overview and future potential. J Control Release. 2009;139:94-107.

32. Choudhary DR, Patel VA, Patel HV, Kundawala AJ. Formulation and evaluation of quick dissolving film of levocetirizine dihydrochloride. Int J Pharm Technol. 2011;3:1740-1749.

33. Sudhakar Y, Kuotsu K, Bandyopadhyay AK. Buccal bioadhesive drug delivery-a promising option for orally less efficient drugs. J Control Release. 2006;114:15-40.

34. Senthilkumar K, Vijaya C. Formulation development of mouth dissolving film of etoricoxib for pain management. Adv Pharm. 2015;1-11.

35. Sivakranth M, Abdul SA, Rajasekhar S. Formulation and evaluation of oral fast dissolving tablets of sildenafil citrate. Int J Pharm Pharm Sci. 2011;3:112-121.

36. Xia $\mathrm{Y}$, Chen $\mathrm{F}$, Zhang $\mathrm{H}$, Luo $\mathrm{C}$. A new method for evaluating the dissolution of orodispersible films. Pharm Dev Technol. 2015;20:375379.

37. Sharma D, Singh G, Kumar D, Singh M. Formulation development and evaluation of fast disintegrating tablets of salbutamol sulphate, cetirizine hydrochloride in combined pharmaceutical dosage form: a new era in novel drug delivery for pediatrics and geriatrics. J Drug Deliv. 2015;2015:640529.

38. Dinge A, Nagarsenker M. Formulation and evaluation of fast dissolving films for delivery of triclosan to the oral cavity. AAPS PharmSciTech. 2008;9:349-356.

39. Kunte S, Tandale P. Fast dissolving strips: a novel approach for the delivery of verapamil. J Pharm Bioallied Sci. 2010;2:325-328.

40. Lai KL, Fang Y, Han H, Li Q, Zhang S, Li HY, Chow SF, Lam TN, Lee WYT. Orally-dissolving film for sublingual and buccal delivery of ropinirole. Colloids Surf B Biointerfaces. 2018;163:9-18.

41. Morales JO, McConville JT. Manufacture and characterization of mucoadhesive buccal films. Eur J Pharm Biopharm. 2011;77:187-199.

42. Murata Y, Isobe T, Kofuji K, Nishida N, Kamaguchi R. Preparation of fast dissolving films for oral dosage from natural polysaccharides. Materials (Basel). 2010;3:4291-4299.
43. Gupta MM, Patel Mitul G, Kedawat M. Enhancement of dissolution rate of rapidly dissolving oral film of meclizine hydrochloride by complexation of meclizine hydrochloride with $\beta$-cyclodextrine. J Appl Pharm Sci. 2011;1:150-153.

44. Prabhu P, Malli R, Koland M, Vijaynarayana K, D'Souza U, Harish N, Shastry C, Charyulu R. Formulation and evaluation of fast dissolving films of levocitirizine di hydrochloride. Int J Pharm Investig. 2011;1:99104.

45. Langoth N, Kalbe J, Bernkop-Schnürch A. Development of buccal drug delivery systems based on a thiolated polymer. Int $\mathrm{J}$ Pharm. 2003;252:141-148.

46. Rao R, Kandhadi SR, Swapna D, Konasree SD, Enugala S. Formulation and evaluation of rapidly dissolving buccal patches. Int J Pharm Bio Sci. 2011;1:145-159.

47. Mashru RC, Sutariya VB, Sankalia MG, Parikh PP. Development and evaluation of fast-dissolving film of salbutamol sulphate. Drug Dev Ind Pharm. 2005;31:25-34.

48. Saini S, Rana A, Gupta S. Optimization of formulation of fast dissolving films made of pullulan polymer. Int J Pharm Sci Rev Res. 2011;9:127-131.

49. Dahiya M, Saha S, Shahiwala AF. A review on mouth dissolving films. Curr Drug Deliv. 2009;6:469-476.

50. Tapash K. Ghosh, William R. Pfister. Drug delivery to the oral cavity: molecules to market. CRC Press; 1st edition: 1-397.

51. Gavaskar B, Kumar SV, Sharan G, Madhusudan Rao Y. Overview on fast dissolving films. Int J Pharm. Pharm Sci. 2010;2:29-33.

52. Mansoori S, Patel MK, Chatterjee DP. Formulation and characterization of oral thin film containing domperidone $\mathrm{HCl}$. Panacea J Pharm Pharm Sci. 2017;6:121-144.

53. Samprasit W, Akkaramongkolporn $\mathrm{P}$, Kaomongkolgit R, Opanasopit $\mathrm{P}$. Cyclodextrin-based oral dissolving films formulation of taste-masked meloxicam. Pharm Dev Technol. 2018;23:530-539.

54. Patel VF, Liu F, Brown MB. Advances in oral transmucosal drug delivery. J Control Release. 2011;153:106-116.

55. Narang N, Sharma J. Sublingual mucosa as a route for systemic drug delivery. Int J Pharm Pharm Sci. 2011;3:18-22.

56. Patel HA, Patel JK, Patel KN, Patel RR. Studies on formulation and in vitro evaluation of fast dissolving tablets of domperidone. Int $\mathrm{J}$ Pharm Sci. 2010;2:470-476.

57. Hearnden V, Sankar V, Hull K, Juras DV, Greenberg M, Kerr AR, Lockhart PB, Patton LL, Porter S, Thornhill MH. New developments and opportunities in oral mucosal drug delivery for local and systemic disease. Adv Drug Deliv Rev. 2012;64:16-28.

58. Nandy BC, Mazumder B, Pathak K, Saxena N, Jain S, Sharma S, Amishaben R, Shrivastava A, Saxena P. An overview on fast dissolving drug delivery system. AJPSR. 2011;1:10-15. 